\title{
AVALIAÇÃO DE TIPOS DE VENTILAÇÃO EM MATERNIDADE DE SUÍNOS
}

\author{
YAMILIA B. TOLON ${ }^{1}$, IRENILZA DE A. NÄÄS ${ }^{2}$
}

RESUMO: As instalações onde os animais fazem o seu ciclo de produção devem ter como característica principal permitir o controle da influência dos fatores climáticos sobre os animais. As variações ambientais podem ser controladas por meio do uso de diferentes sistemas de ventilação. Dessa maneira, o objetivo desta pesquisa foi avaliar a influência de diferentes sistemas de acondicionamento na maternidade de suínos. Foram testados três tratamentos: ventilação natural, ventilação refrigerada e ventilação forçada. Os parâmetros climáticos avaliados foram: temperatura do ar, umidade relativa e temperatura de globo negro. Foram analisados, nas fêmeas, os parâmetros: freqüência respiratória e espessura do toucinho, e nos leitões: número de leitões nascidos vivos, peso médio ao desmame e número de leitões desmamados. O uso do sistema de ventilação refrigerada diminuiu a temperatura do ar e a freqüência respiratória dos animais, e os índices de temperatura globo e umidade (ITGU), e a carga térmica radiante (CTR).

PALAVRAS-CHAVE: suínos, resfriamento, índices de conforto térmico.

\section{EVALUATION OF TYPES OF VENTILATION IN SWINE MATERNITY}

ABSTRACT: Livestock facilities, where animals carry their productive cycle, must have as main characteristic, the control of influence over climatic factors on animals. The environment variations can be controlled through the use of different ventilation systems. The objective of this research was to evaluate the influence of different environment conditioning systems on swine nursery. Three treatments have been tested: natural ventilation, cooled ventilation and forced ventilation. The climatic parameters evaluated were: air temperature, relative humidity and black globe temperature. The physiological parameters analyzed were: respiratory frequency and back fat thickness. Number of born alive piglets, average weight at weaning and number of weaned piglets were also evaluated parameters. The use of cooled ventilation systems were able to decreased animal's air temperature and respiratory frequency, and the black globe temperature and humidity index (WBGT) and the radiating thermal load (RTL).

KEYWORDS: swine, cooling, thermal comfort index.

\section{INTRODUÇÃO}

O aumento da população humana acarreta a necessidade de maiores quantidades de alimentos para satisfazer suas crescentes demandas alimentícias, particularmente as protéicas. É por isso que, a partir da década de 1960, as antigas criações extensivas passaram a se intensificar e ter como característica principal o alojamento de grande número de animais em espaço reduzido. Essa mudança no sistema de criação tornou possível grande aumento na produção de alimentos de origem animal para consumo humano. Por outro lado, trouxe incremento no desconforto dos animais. O suíno é um exemplo de animal cujo conforto vem sendo prejudicado pela intensificação da produção, caracterizada pela restrição do espaço, movimentação e interação social (PUTTEN, 1989), o que traz consigo o detrimento de seu conforto térmico, assim como da sua produtividade. A determinação das

\footnotetext{
${ }^{1}$ Doutora, DECR/FEAGRI/UNICAMP, Caixa Postal 6011, Campinas - SP, yamilia.tolon @agr.unicamp.br

${ }^{2}$ Prof. Titular, DECR/FEAGRI/UNICAMP, Caixa Postal 6011, Campinas - SP, Fone: (0XX19) 3788 1039, irenilza@agr.unicamp.br Recebido pelo Conselho Editorial em: 9-1-2003

Aprovado pelo Conselho Editorial em: 22-8-2005
} 
exigências de bem-estar animal em relação à saúde e à economicidade da produção constitui grande desafio para a simplificação do manejo, redução de custos e aumento da produtividade (ENGLISH \& EDWARDS, 1992).

O desempenho produtivo e reprodutivo dos animais depende do sistema de manejo empregado, que envolve o sistema de criação escolhido, da nutrição, da sanidade e das instalações. Essas instalações, que demandam maior volume de investimento fixo inicial, são construídas em função dos custos e facilidades para o tratador, ficando negligenciado o conforto do animal. No caso da maternidade, esse problema se evidencia por conviverem nela duas categorias com exigências ambientais muito diferentes, pois a porca precisa ser refrigerada, e o leitão, por outro lado, precisa ser aquecido. A solução dessa problemática, presente em todas as granjas de suínos, é prioritária quando se pretende melhorar o desempenho de ambas as categorias.

O objetivo deste trabalho foi avaliar a eficiência de técnicas de ventilação (natural, forçada e resfriada) em maternidade de suínos com base em índices de ambiente térmico (ITGU, CTR e umidade relativa) e resposta fisiológica dos animais (freqüência respiratória, produtividade e espessura de toucinho).

\section{MATERIAL E MÉTODOS}

O trabalho foi realizado na cidade de Campinas - SP, no período de outubro de 1998 a março de 2001. Esse local pode ser caracterizado como de clima subtropical, seco no inverno, com temperatura média anual de $24,5^{\circ} \mathrm{C}$ e precipitação média anual de $1.360 \mathrm{~mm}$, tendo latitude de $22^{\circ} 54^{\prime} \mathrm{S}$, longitude de $47^{\circ} 05^{\prime} \mathrm{W}$ e altitude de $674 \mathrm{~m}$. Foram utilizadas três salas de maternidade, sendo os resultados interpretados estatisticamente por meio de análises de variância, utilizando o programa SAS.

As matrizes permaneceram nessas salas até o desmame dos leitões, que aconteceu aos 21 dias de seu nascimento. O total de animais utilizados para este experimento (não balanceado) é de 316 matrizes pertencentes às genéticas Dalland e Agroceres PIC. O experimento possui quatro fontes de variação: sistemas, número de parto (primípara ou multípara), estação (inverno ou verão) e origem genética (Dalland ou Agroceres PIC), sendo o sistema a fonte principal de variação, contendo três níveis; as demais fontes de variação são secundárias (ator de blocagem), com dois níveis cada.

$\mathrm{Na}$ realização do presente trabalho, foram testados os seguintes tratamentos: ventilação natural (sem presença de equipamento de ventilação), ventilação refrigerada (uso de condicionador adiabático e ventilação forçada (uso de ventilador). A disposição dos tratamentos na instalação pode ser observada na Figura 1.

A instalação usada para o experimento tinha como características construtivas:

Telhado: composto por telhas de alumínio pintadas de branco;

Paredes: blocos de concreto, recobertas com argamassa e pintadas de branco;

Dimensões das salas: 12,5 m de comprimento e $10 \mathrm{~m}$ de largura;

Altura do pé-direito: $3 \mathrm{~m}$, e

Orientação: leste-oeste.

O equipamento de resfriamento utilizado no tratamento com ventilação refrigerada é denominado condicionador adiabático (Figura 2). Ele funciona com base no resfriamento do ar por um processo isoentálpico por meio da cessão do calor sensível contido no ar em contato com a superfície líquida. Esse processo é feito pela lavagem do fluxo de ar, propiciando a sua purificação constante e contínua. $\mathrm{O}$ aparelho é composto por placas de filtro adiabático tipo colméia, com ampla superfície úmida, onde são realizadas as lavagens e a retirada do calor sensível. Foram colocados, na entrada do 
aparelho, tubos de PVC de $150 \mathrm{~mm}$ de diâmetro, dirigidos para dentro das salas, conduzidos até a parte superior da cabeça das matrizes, fornecendo, assim, ar mais frio do que o do exterior (tratamento 2).

O tratamento 1 ou de ventilação natural não constava de nenhum equipamento de ventilação, e as aberturas laterais (janelas) apresentavam 1,29 m de altura, comprimento de 12,5 m, estendendo-se por todo o galpão, possuindo peitoril de $1,71 \mathrm{~m}$; já, para o tratamento 3 ou ventilação forçada, foi usado um ventilador axial de $0,735 \mathrm{~kW}(1 \mathrm{cv})$.

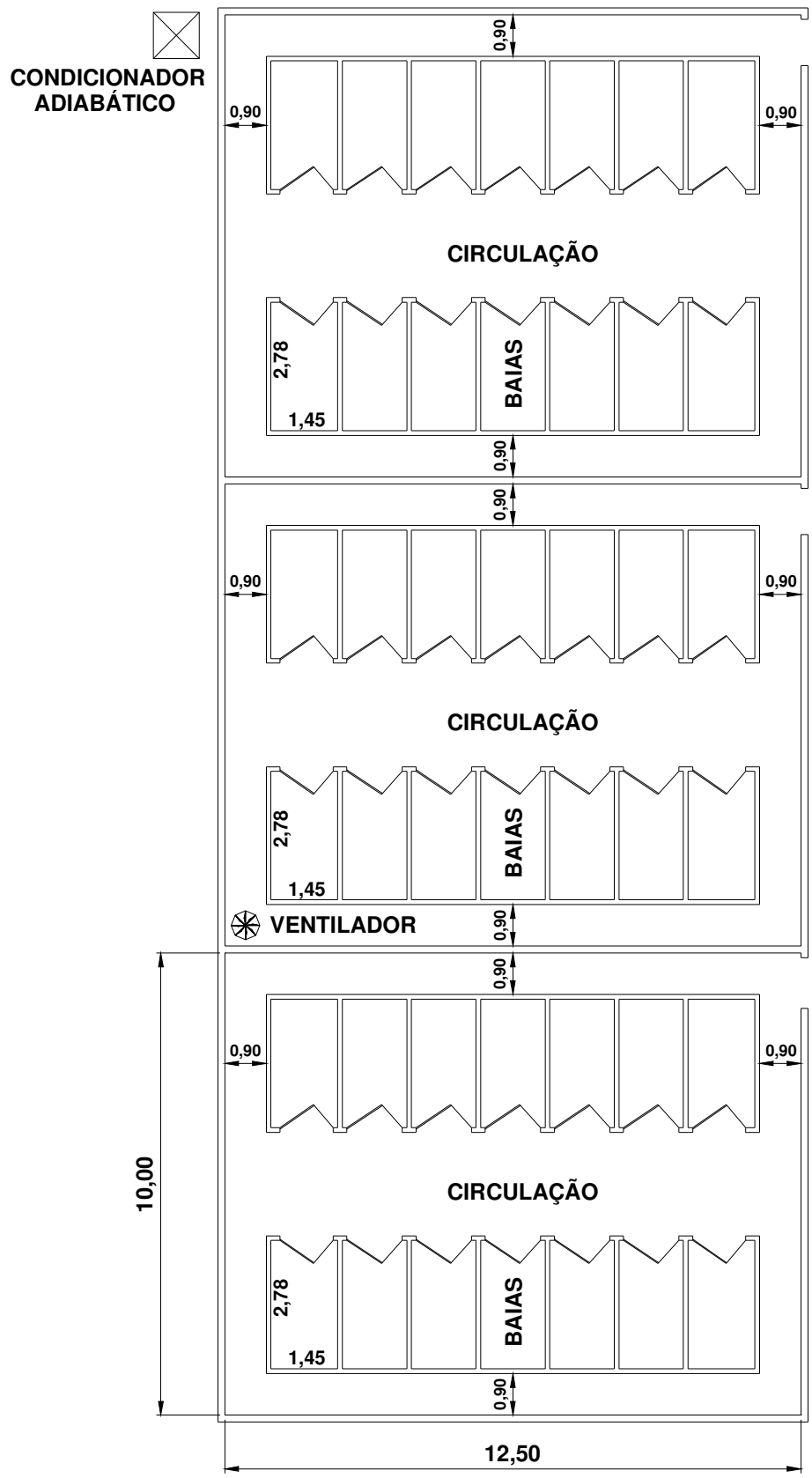

FIGURA 1. Esquema da disposição dos tratamentos nas salas de maternidade (dimensões em metro). 


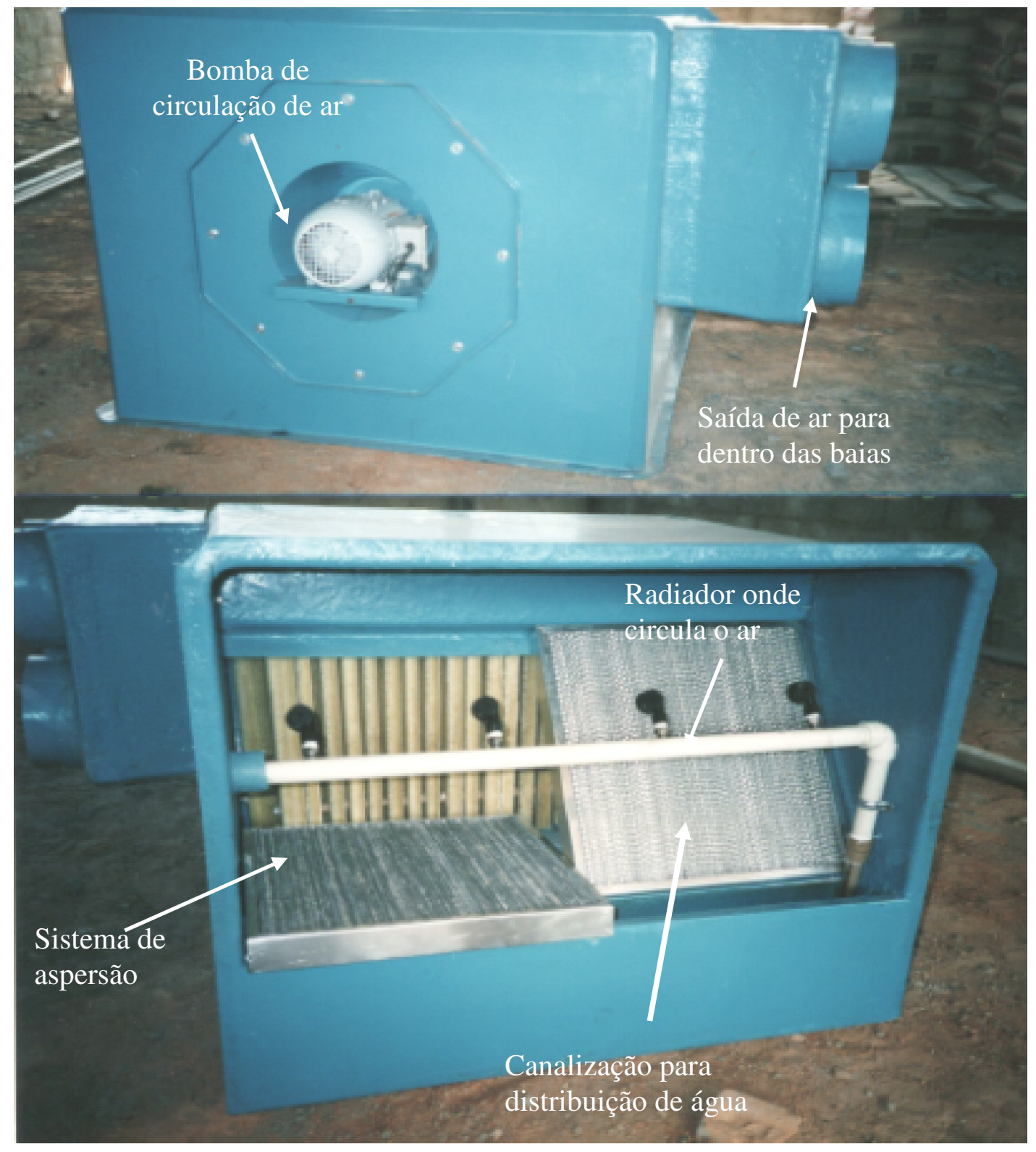

FIGURA 2. Vista frontal e lateral do equipamento de resfriamento evaporativo adiabático utilizado na maternidade.

Foram tomadas as seguintes medidas ambientais:

- Temperatura de bulbo seco (TBS) e umidade relativa (UR): foi utilizado um registrador eletrônico da marca TESTO ${ }^{\circledR}$;

- Velocidade do ar (V): utilizou-se, como instrumento de medição, de um anemômetro digital da marca KESTREL ${ }^{\circledR} 1000$, e

- Temperatura de globo negro (TG): utilizou-se de termômetro de mercúrio inserido em uma esfera negra e fosca, a qual estava ligada a um registrador eletrônico que possuía um sensor de temperatura interno (temperatura ambiente) e um sensor externo (temperatura de globo negro). 
Os instrumentos citados foram instalados no centro geométrico das salas a uma altura de 1,5 m. Todas as medidas foram realizadas em intervalos igualmente espaçados de 30 minutos. Os dados coletados foram registrados de acordo com a época do ano (inverno ou verão).

Realizaram-se, ainda, medidas referentes ao próprio animal, sendo:

- Freqüência respiratória: foi obtida com base na observação dos movimentos do flanco de cada animal, por cerca de um minuto, entre 10 e 11 horas da manhã;

- Espessura de toucinho: a mensuração da espessura do toucinho foi feita na altura da última costela, subindo $6 \mathrm{~cm}$ no sentido da coluna, por meio do aparelho digital "backfat indicator". Para essa medida, dividiram-se os animais em duas categorias, de acordo como o número de parto (primípara ou pluríparas) e origem genética (Dalland ou Agroceres PIC), e

- Produtividade: foram obtidas no final de cada ciclo de produção, com base no software PIGCHAMP $^{\circledR}$, como segue: número de leitões nascidos vivos $(\mathrm{NV})$, peso médio ao desmame (PMDESM) e número de leitões desmamados (NLDESM).

\section{RESULTADOS E DISCUSSÃO}

Os resultados correspondentes ao parâmetro climático temperatura de bulbo seco (TBS) são apresentados na Tabela 1 .

TABELA 1. Médias de temperatura de bulbo seco (TBS) nos tratamentos.

\begin{tabular}{lcc}
\hline \multicolumn{1}{c}{ Tratamentos } & Médias de TBS $\left({ }^{\circ} \mathrm{C}\right)$ & Desvio-Padrão das Médias \\
\hline Ventilação natural & $24,9 \mathrm{a}$ & 0,068 \\
Ventilação refrigerada & $24,3 \mathrm{~b}$ & 0,042 \\
Ventilação forçada & $24,8 \mathrm{a}$ & 0,088 \\
\hline
\end{tabular}

Letras diferentes representam diferenças significativas $(\mathrm{P}<0,05)$, pelo teste de Tukey.

Pelos resultados obtidos na análise estatística, pode-se observar que existe diferença significativa $(\mathrm{P}<0,05)$ na TBS, dos tipos de ventilação testados, indicando que o ambiente da sala foi influenciado pela ventilação adotada. $O$ resultado mostrou que o tratamento de ventilação refrigerada foi o que apresentou menor temperatura de bulbo seco (TBS $=24,3^{\circ} \mathrm{C}$ ). Esse resultado indica que, com o uso do equipamento de refrigeração adiabática localizado sobre as porcas, foi possível diminuir a temperatura dentro da sala de maternidade. Entretanto, essa diminuição não foi o suficiente para atingir a temperatura de conforto $\left(18,3^{\circ} \mathrm{C}\right)$ para porcas na maternidade, sugerida por VEIT \& TROUTT (1982). Coincidindo também com o encontrado por AXAOPOULOS et al. (1992), um sistema de ventilação, ainda que capaz de manter a amplitude térmica na faixa recomendada ( 1 a $3{ }^{\circ} \mathrm{C}$ ), não pode assegurar completamente a prevenção de estresse térmico, especialmente no verão, em que a temperatura interna supera a temperatura crítica superior do animal. Quanto à umidade relativa, os resultados são apresentados na Tabela 2 .

TABELA 2. Médias de umidade relativa nos tratamentos.

\begin{tabular}{lcc}
\hline \multicolumn{1}{c}{ Tratamentos } & Médias de Umidade Relativa (\%) & Desvio-Padrão das Médias \\
\hline Ventilação natural & $75,06 \mathrm{c}$ & 0,302 \\
Ventilação refrigerada & $92,54 \mathrm{a}$ & 0,139 \\
Ventilação forçada & $76,10 \mathrm{~b}$ & 0,336 \\
\hline
\end{tabular}

Letras diferentes representam diferenças significativas $(\mathrm{P}<0,05)$, pelo teste de Tukey.

O tratamento que teve o maior valor de umidade relativa, foi o de ventilação refrigerada (UR $=92,54 \%$, pois o equipamento utilizado refrigera o ar a partir da evaporação da água. Com esse 
resultado, pode-se concluir que a refrigeração adiabática deve ser utilizada de forma controlada, uma vez que contribui para o aumento da umidade relativa dentro da sala, acima do valor ótimo para suínos (60 a 80\%), conforme recomendado por BENEDI (1986). Esses resultados confirmam aqueles obtidos por BAÊTA \& SOUZA (1997), demonstrando que o uso de sistemas de resfriamento adiabático propicia queda na temperatura de bulbo seco e aumento na umidade do ambiente. Os resultados do índice de temperatura de globo e umidade (ITGU) são apresentados na Figura 3.

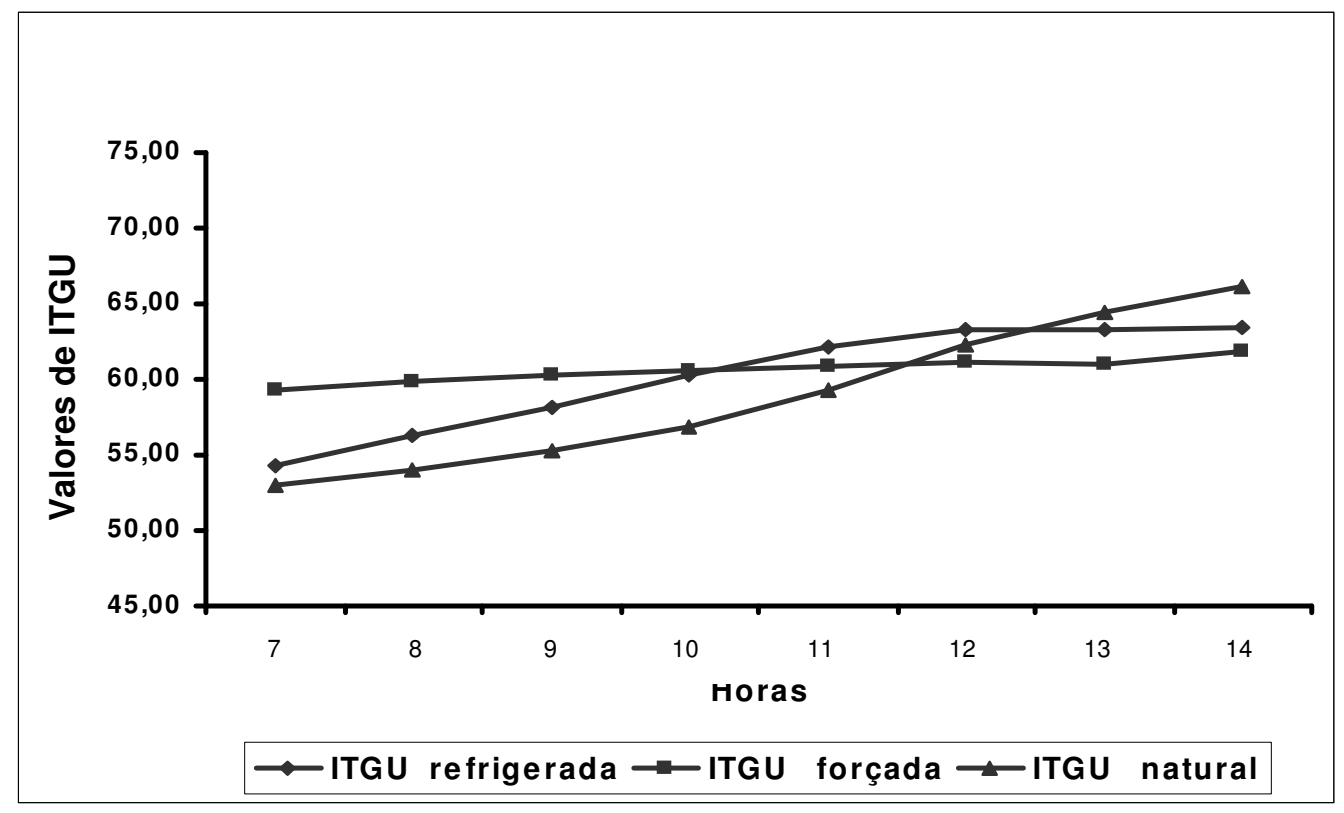

FIGURA 3. Gráfico de ITGU por tratamento, no período das 7 às $14 \mathrm{~h}$.

BUFFINGTON et al. (1981) afirmaram que o índice mais preciso para medir o conforto térmico dos animais, é o índice de temperatura de globo e umidade (ITGU). Esse índice determina a influência do efeito combinado da temperatura de bulbo úmido, da velocidade do ar, da temperatura ambiente e da temperatura de globo negro. Segundo COELHO et al. (2001), a temperatura de globo negro é um valor influenciado pelas temperaturas radiantes das superfícies visualizadas pelo termômetro de globo, pela temperatura de ar circundante e pela velocidade do ar na posição da medição.

De acordo com a Figura 3, pode-se observar que os tratamentos estudados no início do dia apresentaram valores de ITGU menores, mas houve diferenças entre os tratamentos estudados. No entanto, a partir do meio-dia, esse comportamento começa a mudar, e nota-se que o tratamento de ventilação natural começa a aumentar seus valores, alcançando o nível máximo às 14 h. Precisamente nesse horário, os tratamentos de ventilação forçada e ventilação refrigerada mostraram os menores valores de ITGU, sendo indicativo de que, nesses ambientes, ou tratamentos, os animais estavam em melhores condições de conforto. Esses resultados concordam com os obtidos por TINÔCO (1987), que informou que os valores mínimos de ITGU ocorreram durante o período da manhã, e os máximos, entre o meio-dia e as $14 \mathrm{~h}$.

Na Figura 4, encontra-se a representação gráfica da carga térmica radiante (CTR), em função dos tratamento. Pode-se observar que, durante o período crítico do dia, das 12 às $14 \mathrm{~h}$, o tratamento que apresentou a menor carga térmica radiante (CTR) foi o de ventilação refrigerada, mostrando que esse sistema foi o que proporcionou as melhores condições ambientais aos animais. Esses resultados concordam com os obtidos por TURCO (1993) em experimento feito, comparando os efeitos de ventilação forçada com ar natural e ar resfriado evaporativamente, localizados próximos à região da cabeça e somente com ar resfriado evaporativamente sobre todo o corpo de porcas lactantes. 


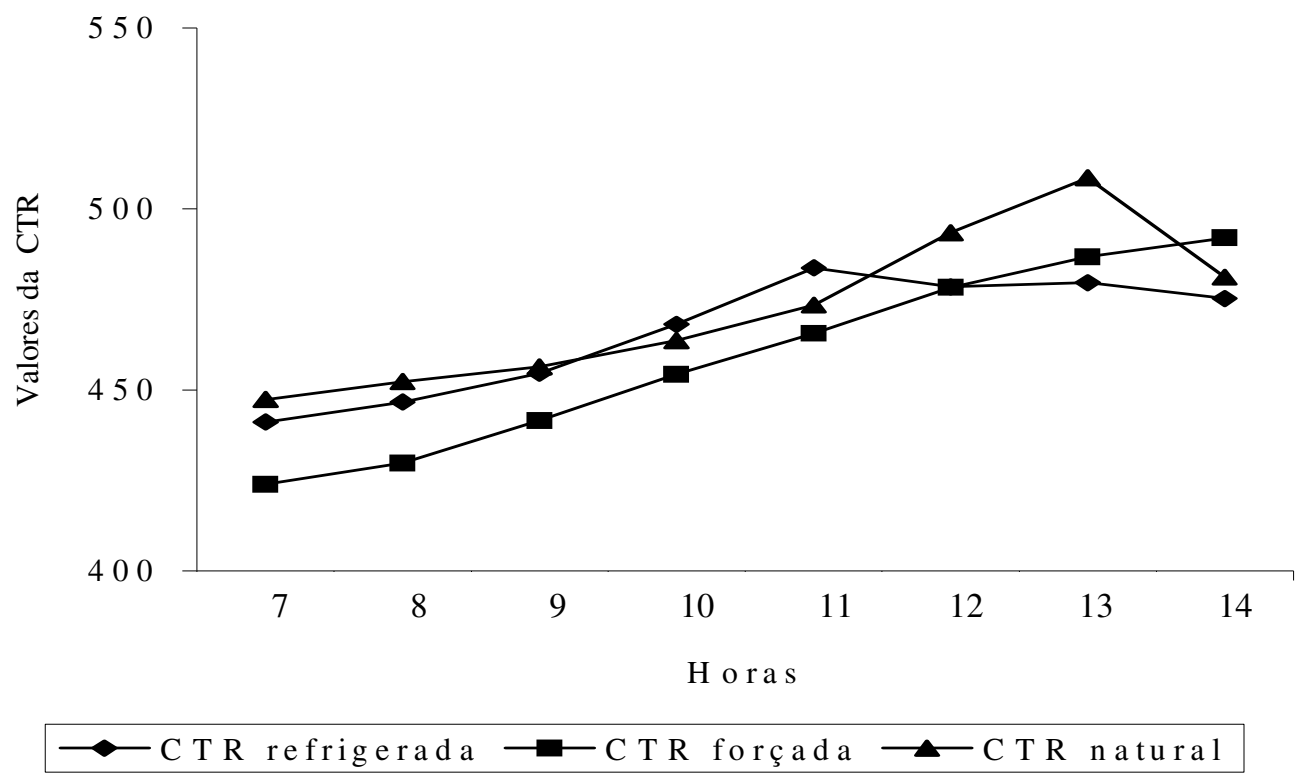

FIGURA 4. Carga térmica radiante por tratamento, no período das 7 às 14 h.

Na Tabela 3, são apresentados os resultados da análise de variância para o parâmetro fisiológico de frequiência respiratória. Os resultados indicam que existem diferenças significativas $(\mathrm{P}<0,05)$ entre os diferentes tratamentos para a freqüência respiratória.

TABELA 3. Médias dos tratamentos para freqüência respiratória das porcas.

\begin{tabular}{lcc}
\hline \multicolumn{1}{c}{ Fatores } & Médias (mov./minuto) & Desvio-Padrão das Médias \\
\hline Ventilação natural & Sistemas & \\
Ventilação refrigerada & $54,4 \mathrm{~b}$ & 1,773 \\
Ventilação forçada & $50,2 \mathrm{a}$ & 1,910 \\
\hline & $57,8 \mathrm{c}$ & 2,419 \\
\hline Inverno & Estação & 1,663 \\
Verão & $52,80 \mathrm{a}$ & 1,809 \\
\hline
\end{tabular}

Letras diferentes representam diferenças significativas $(\mathrm{P}<0,05)$, pelo teste de Tukey.

A ventilação refrigerada foi a que proporcionou menor valor de freqüência respiratória, o que indica que os animais desse tratamento tiveram maior sensação de conforto. Os dados apresentados correspondem ao microclima geral do galpão, mas o tratamento de ventilação refrigerada é direcionado diretamente ao hipotálamo da matriz (ou seja, a ventilação refrigerada influenciou na porca e não no microclima do galpão), observando menor freqüência respiratória $(50,2)$ quando comparado com os outros tratamentos estudados, ou seja, ventilação forçada $(57,8)$ e natural $(54,4)$.

Os resultados aqui obtidos podem ser comparados com os obtidos por BULL et al. (1997), que analisaram o desempenho de marrãs em sistemas de resfriamento (resfriamento adiabático, gotejamento e resfriamento no focinho) e mediram a temperatura retal e a taxa de respiração, concluindo que os animais preferem o resfriamento adiabático, ou seja, as trocas de calor por condução, apresentando menor taxa de respiração e menor temperatura retal. Os resultados dos valores das médias obtidos são apresentados na Tabela 4. 
TABELA 4. Médias da covariância da espessura de toucinho (ET).

\begin{tabular}{lcc}
\hline \multicolumn{1}{c}{ Fatores } & Médias $(\mathrm{mm})$ & Desvio-Padrão das Médias \\
\hline Co-variável ET entrada & 17,61 & 2,439 \\
\hline Ventilação natural & Sistemas & 0,09386 \\
Ventilação refrigerada & $14,55 \mathrm{c}$ & 0,09997 \\
Ventilação forçada & $14,89 \mathrm{~b}$ & 0,12576 \\
\hline & $14,94 \mathrm{a}$ & 0,10029 \\
\hline Primíparas & Número de Partos & 0,08324 \\
Pluríparas & $14,79 \mathrm{a}$ & 0,08699 \\
& $14,80 \mathrm{a}$ & 0,09488 \\
\hline Inverno & Estação & 0,06242 \\
Verão & 14,83 a & 0,13145 \\
\hline
\end{tabular}

Letras diferentes representam diferenças significativas $(\mathrm{P}<0,05)$, pelo teste de Tukey.

Por meio da análise de co-variância, leva-se em consideração que a espessura de toucinho no $\mathrm{T}_{0}$ cresce de forma linear (sendo assim uma co-variável), permitindo análise mais apurada dos dados para espessura de toucinho no $\mathrm{T}_{1}$ (saída).

De acordo com o valor $\mathrm{P}<0,05$ mostrado, existem diferenças significativas na espessura do toucinho na entrada dos tratamentos. Foram encontradas, também, diferenças significativas na espessura de toucinho na saída dos tratamentos, especificamente no tratamento de ventilação forçada, que apresentou o melhor resultado, seguido do tratamento de ventilação refrigerada, mostrando que os sistemas de climatização empregados tiveram efeito positivo sobre os animais. Esses resultados são coincidentes com os obtidos por AHERNE \& FOXCROFCT (2000), que encontraram que a temperatura ambiente é um dos fatores mais importantes que influem na espessura de toucinho dos animais na etapa de lactação.

Os resultados aqui encontrados são semelhantes aos obtidos por DERMO et al. (1995) que, em estudo feito na morfologia de suínos submetidos a diferentes temperaturas ambientes, mostraram a espessura do toucinho maior em animais submetidos à temperatura de $12{ }^{\circ} \mathrm{C}$ do que nos animais submetidos a $24{ }^{\circ} \mathrm{C}$.

$\mathrm{Na}$ Tabela 5, são apresentados os resultados de número de leitões desmamados. Verificou-se que não houve diferenças significativas $(\mathrm{P}>0,05)$ entre os diferentes tratamentos, para o número de leitões desmamados. Nota-se ligeira melhoria no número de leitões desmamados para as fêmeas pluríparas, o que está de acordo com os resultados obtidos por PINHEIRO et al. (2002). Esse resultado concorda também com o encontrado por CLARK \& LEMAN (1986). Esses autores relataram vários fatores que influenciam no número de leitões desmamados, como, por exemplo: ordem de parto, idade da concepção da primeira leitegada e número de coberturas por cio.

CABRERA (2001) observou que altas temperaturas podem afetar a reprodutora na maternidade, diminuindo o consumo de alimentos em $40 \%$. Além disso, esse fator produz redução da espessura do toucinho, provoca o aumento do intervalo do desmame e do cio, diminuindo em $30 \%$ a produção de leite, mas não a composição do mesmo, diminuindo o tamanho da leitegada e o período de lactação. Na Tabela 6, são mostradas as médias do parâmetro ganho de peso médio dos leitões desmamados. 
TABELA 5. Médias do número de leitões desmamados nos tratamentos.

\begin{tabular}{crc}
\hline \multicolumn{1}{c}{ Fatores } & Médias & Desvio-Padrão \\
\hline & Sistemas & \\
\hline Ventilação natural & 9,34 a & 0,1618 \\
Ventilação refrigerada & 8,81 a & 0,1743 \\
Ventilação forçada & 9,18 a & 0,2208 \\
\hline
\end{tabular}

Letras diferentes representam diferenças significativas $(\mathrm{P}<0,05)$, pelo teste de Tukey.

TABELA 6. Médias de ganho de peso médio nos tratamentos.

\begin{tabular}{lcc}
\hline \multicolumn{1}{c}{ Fatores } & Médias $\left(\mathrm{g} \mathrm{dia}^{-1}\right)$ & Desvio-Padrão \\
\hline Ventilação natural & Sistemas & 4,304 \\
Ventilação refrigerada & $289,5 \mathrm{a}$ & 4,636 \\
Ventilação forçada & $298,2 \mathrm{a}$ & 5,872 \\
\hline & $284,6 \mathrm{a}$ & \\
\hline Primíparas & Número de Partos & 4,646 \\
Pluríparas & $278,7 \mathrm{~b}$ & 3,876 \\
\hline & $302,8 \mathrm{a}$ & 4,037 \\
\hline Inverno & Estação & 4,391 \\
Verão & $290,7 \mathrm{a}$ & \\
\hline & $290,9 \mathrm{a}$ & 2,910 \\
\hline Dalland & Genética & 6,039 \\
Agroceres PIC & $291,9 \mathrm{a}$ & \\
\hline
\end{tabular}

Letras diferentes representam diferenças significativas $(\mathrm{P}<0,05)$, pelo teste de Tukey

Os resultados obtidos para ganho de peso médio dos leitões indicam que esse parâmetro somente foi significativo para o fator parto, ou seja, os leitões nascidos de porcas pluríparas foram os que tiveram maior ganho de peso médio. Esses dados diferem dos encontrados por PERDOMO (1995), que menciona maior ganho de peso nos leitões na época mais fria do ano, sugerindo efeito positivo das temperaturas mais baixas nas porcas em lactação. Os resultados obtidos também diferem dos obtidos por TEIXEIRA \& TEIXEIRA (2004).

\section{CONCLUSÕES}

Os sistemas de climatização artificial empregados (ventilação refrigerada e ventilação forçada) proporcionaram melhoria nas condições térmicas ambientais dentro das instalações, influenciando na resposta produtiva dos animais.

\section{REFERENCIAS}

AHERNE, F.; FOXCROFT, G. Manejo da leitoa e da porca primípara: Parte V. Manejo nutricional na gestação e lactação. In: SIMPÓSIO INTERNACIONAL DE REPRODUÇÃO E INSEMINAÇÃO ARTIFICIAL EM SUÍNOS, 7., 2000, Foz de Iguaçu. Anais...p.106-9.

AXAOPOLOS, P.; PANAGAKIS, P.; KYRITSIS, S. Computer simulation assessment of the thermal microenvironment of growing pigs under summer conditions. Transactions of the ASAE, St. Joseph, v.35, n.3, p.1005-9,1992.

BAÊTA, F. da COSTA; SOUZA, C. de F. Ambiência em edificações rurais - conforto animal. Viçosa - MG: Editora UFV, 1997. 246 p. 
BENEDI, J.M.H. El ambiente de los alojamientos Ganaderos. Ministério de Agricultura, Pesca y Alimentación, Servicio de Extensión Agrária. Madrid: Hojas Divulgadoras, 1986. n.6/86 hd. 28 p.

BUFFINGTON, D.E.; COLLAZO AROCHO, A.; CANTON, G.H.; PITT, D. Black globe-humidity index (BGHI) as a comfort equation for dairy cows. Transactions of the ASAE, St. Joseph, v.24, n.3, p.711-14, 1981.

BULL, R.P.; HARRISON, P.C.; RISKOWSKI, G.L.; GONYOU, H.W. Preference among cooling systems by gilts under heat stress. Journal of Animal Science, Champaign, v.78, n.8, p.2078-83, 1997.

CABRERA, R. Abate com peso elevado: A experiência americana. Disponível em: $<$ http//www.suino.com.br>. Acesso em: 15 jul. 2002.

CLARK, L.K.; LEMAN, A.D. Factors that influence litter size in pigs. Part 1. Pig News and Information, Farham Royal, v.7, p.303-10, 1986.

COELHO, E.; TIBIRIÇÁ, A.C.G.; BAÊTA, F.C.; TINÔCO, I. F. F. Avaliação de condições ambientais em sistemas de confinamento intensivo para produção de leite. In: ENCONTRO NACIONAL SOBRE CONFORTO NO AMBIENTE CONSTRUÍDO, 6., ENCONTRO LATINOAMERICANO SOBRE CONFORTO NO AMBIENTE CONSTRUÍDO, 3., 2001, São Pedro. Anais... 1 CD-ROM.

DERMO, M.; JENTASCH, W.; HOFFMANN, L. Effect of long time exposure to different environment temperatures on heat production of growing pigs. Livestock Production Science, Amsterdam, v.43, n.2, p.149-52, 1995.

ENGLISH, P.R.; EDWARDS, S.A. Animal welfare. In: LEMAN, A.D.; STRAW, B.E.; MENGELING, W.L. Disease of swine $.7^{\text {th }}$ ed. Ames: The Iowa State University, 1992. p.901-8. PERDOMO, C.C. Avaliação de sistemas de ventilação sobre o condicionamento ambiental e o desempenho de suínos na fase de maternidade. 1995. 239 f. Tese (Doutorado em Produção Animal) Faculdade de Agronomia, Universidade Federal do Rio Grande do Sul, Porto Alegre, 1995.

PINHEIRO, J.P.; GALVÃO, R.J.D.; NETO, F.B.; ESPINDOLA, G.B. Características reprodutivas de suínos puros na região semi-árida do Rio Grande do Norte. I. Tamanho da leitegada. 2002. Disponível em: <http://www.porkworld.com.br/ trabalhos técnicos_natimortalidade_em suínos.html>. Acesso em: 15 maio 2004.

PUTEN, G. Van. The pig: Model for discussing animal behavior and welfare. Applied Animal Behavior Science, Amsterdam, v.22, v.2, p.115-28, 1989.

TEIXEIRA, V.H.; TEIXEIRA, A.S. Resfriamento adiabático evaporativo em maternidade de suínos: I Efeito no índice de conforto térmico (ITGU). Disponível em:

<http://www.sbz.org.br/eventos/Fortaleza/Bioclima /Sbz 384.pdf>. Acesso em: 20 jul. 2004.

TINÔCO, I.F.F. Resfriamento adiabático (evaporativo) na produção de frangos de corte. $1987.92 \mathrm{f}$. Dissertação (Mestrado em Construções Rurais e Ambiência) - Faculdade de Engenharia Agrícola, Viçosa - MG, 1987.

TURCO, N.S.H.; BAÊTA, F.C. Modificações das condições ambientais de verão em maternidade de suínos. 1993. 59 f. Dissertação (Mestrado em Construções Rurais e Ambiência) - Faculdade de Engenharia Agrícola, Viçosa - MG, 1993.

VEIT, H.P.; TROUTT, H.F. Monitoring air quality for livestock respiratory health. Veterinary Medicine and Small Animal Clinician, Lenexa, v.77, p.454-64, 1982. 